DR AMAR BHIDE (Orcid ID : 0000-0003-2393-7501)

DR ASMA KHALIL (Orcid ID : 0000-0003-2802-7670)

PROFESSOR BASKY THILAGANATHAN (Orcid ID : 0000-0002-5531-4301)

Article type : Original Research Article

\title{
Lower uterine segment placental thickness in women with abnormally invasive placenta
}

Amarnath BHIDE ${ }^{1}$, Arianna LAORETI ${ }^{1}$, Andrea KAELIN AGTEN ${ }^{1}$, Aris

PAPAGEORGHIOU $^{1}$, Asma KHALIL ${ }^{1}$, James UPRICHARD ${ }^{2}$, Basky THILAGANATHAN ${ }^{1}$

\& Edwin CHANDRAHARAN ${ }^{1}$

${ }^{1}$ Department of Obstetrics \& Gynecology and ${ }^{2}$ Department of Hematology, St. George's

University Hospital Foundation trust and St. George's, University of London, London, UK

\section{Address for correspondence:}

Amarnath Bhide

Fetal Medicine Unit, Lanesborough Wing, $4^{\text {th }}$ Floor, St. George's Hospital, Blackshaw Road, SW17 0QT London, UK

Email : abhide@sgul.ac.uk

\section{Conflicts of Interest notification:}

The authors report no conflict of interest.

\section{FUNDING}

There was no specific funding for this study.

\section{ABSTRACT}

Introduction: Ultrasound signs of abnormal placental invasion are subjective in nature. We tested the hypothesis that placental thickness in the lower uterine segment is increased when there is abnormally invasive placenta (AIP) in women with a low-lying placenta. Material

This article has been accepted for publication and undergone full peer review but has not been through the copyediting, typesetting, pagination and proofreading process, which may lead to differences between this version and the Version of Record. Please cite this article as doi: 10.1111/aogs.13422

This article is protected by copyright. All rights reserved. 
and methods: Retrospective analysis of data of placental thickness in women with ultrasound evidence of major placenta previa or a low-lying anterior placenta. The diagnosis of AIP was confirmed both intraoperatively and on histopathology for those managed by partial myometrial excision with uterine conservation or by hysterectomy. Results: One hundred and thirty-one records were available for analysis after exclusion of 33 cases due to unsuitable images and 8 cases without pregnancy outcomes. The diagnosis of AIP was confirmed in $28(21.4 \%)$ of the 131 cases. The lower segment placental thickness was significantly higher in women with AIP (median=50.3mm, IQR: 42.7 to 64.3) compared to those with normal placentation (median=30.9mm, IQR: 22.9 to 42.2, p<0.001). Logistic regression analysis showed that previous cesarean section and placental thickness on ultrasound were independent predictors for AIP. Conclusion: Lower uterine segment placental thickness is increased in women with AIP compared to those with non-invasive placentation. This association constitutes a pragmatic objective sign and may be of clinical value in improving prenatal detection of AIP in women with placental implantation in the lower uterine segment. Prospective studies are necessary to ascertain lower segment placental thickness as a predictor for AIP.

\section{Key words:}

Placenta accreta, Ultrasound, Placental thickness, Abnormal invasive placenta

\section{ABBREVIATIONS}

AIP - abnormally invasive placenta

\section{Key message:}

Placental thickness in the lower uterine segment is significantly greater in women with abnormally invasive placenta as compared to those with normal placentation. This is a useful objective sign to improve prenatal detection of abnormal placental invasion.

\section{INTRODUCTION}

Abnormally invasive placenta (AIP), also sometimes termed as abnormally invasive placentation (AIP) is an uncommon complication, but is associated with serious maternal morbidity and mortality $(1,2)$. The incidence of AIP appears to be increasing, with the rising rate of cesarean section birth thought to be a major predisposing factor to this

This article is protected by copyright. All rights reserved. 
complication(3). Prenatal diagnosis of AIP has been shown to reduce maternal morbidity associated with this condition, most likely due to the opportunity to plan management in advance(4). Ultrasound is the primary investigation for prenatal diagnosis of morbidly adherent placenta, and the diagnostic accuracy is good both in retrospective, as well as prospective case series $(5,6)$. Nevertheless, many markers of invasive placentation are subjective in nature. Objective markers are likely to improve reproducibility.

Antenatal diagnostic signs of morbidly adherent placenta are best described in the cohort of women with previous cesarean birth and anterior low-lying placenta/placenta previa(6). Implantation of the placenta in the cesarean scar is considered the most likely etiology of AIP with placenta previa. Indeed, there is a growing body of evidence suggesting that a vast proportion of cesarean scar pregnancies progress to AIP in the absence of medical intervention(7-9). Presence of placental lacunae on ultrasound is a reliable sign of $\operatorname{AIP}(10$, 11 ), and is thought to occur because defective placentation from high velocity jets of maternal blood into the placental sinuses.

With placental implantation into the cesarean section scar, the center of the placental disc would be in the vicinity of the lower uterine scar. On the other hand, if placental implantation was near the scar but not in it, only the thinner placental margin may encroach into the lower uterine segment. We therefore hypothesized that the placenta is thicker with AIP in women with a low-lying placenta or placenta previa.

\section{MATERIAL AND METHODS}

We searched the computerized database of the Obstetric ultrasound unit to identify all women with a third trimester diagnosis of complete placenta previa or anterior low-lying placenta. Placenta was defined as low lying if the leading placental edge was within $20 \mathrm{~mm}$ from the internal os (12). The lower uterine segment was identified as the part of the uterus between the cervix and the top of the urinary bladder(13). The maximum placental thickness in the lower uterine segment was measured on stored digital images (Figure 1). 2-D images obtained using trans-abdominal ultrasound scan were used. For the image to be deemed suitable, a midline sagittal section of the lower uterine segment (with the implanted placenta) and the cervical canal, with the intervening urinary bladder was required. The measurement was performed by a researcher (AL) blinded to the final diagnosis. When there was more

This article is protected by copyright. All rights reserved. 
than one third trimester ultrasound examination performed, the one when the patient was first seen for ultrasound scan, was selected for image retrieval. The largest measurement was included if more than one digital images were stored. Basic demographic and pregnancy information, including gestational age was also retrieved. We retrieved information regarding morbidity associated with the surgical procedure, and use and volume of transfusion of blood products. The diagnosis of morbidly adherent placentation was based on intra-operative findings and histopathological examination of the surgical specimen when available. Written confirmation was obtained from the ethics committee that a formal approval was not necessary to analyze routinely collected data retrospectively.

Distribution of data was tested for normality with Kolmogorov Smirnoff test. Accordingly, appropriate tests were used to compare data from women with or without invasive placentation. Chi squared test was used for comparing proportions, and Spearman's rho to test the correlation between gestational age at ultrasound and placental thickness. In order to control for the effect of gestational age, we conducted a logistic regression analysis using gestational age at ultrasound, placental thickness and previous cesarean delivery as covariates. Maternal demographics in excluded cases were compared with the study dataset to explore if there were systematic differences between the two. Statistical Package for Social Sciences (SPSS) version 20, 2011 (IBM Corp, Armonk, USA) was used for all statistical analysis. Statistical significance was set at $p<0.05$.

\section{Ethical approval}

National guidance in the UK mandates that formal ethics approval is not necessary for retrospective analysis of de-identified patient data (http://www.hradecisiontools.org.uk/research/docs/DefiningResearchTable_Oct2017-1.pdf).

\section{RESULTS}

The pregnancy records of 172 women were identified and recovered. 41 records were excluded because either stored images were unsuitable $(n=33)$ or outcome of pregnancy was not available $(\mathrm{n}=8)$, leaving complete data from 131 records available for analysis. Of these 131 women $28(21.3 \%)$ had AIP. The mean maternal age, height, booking weight, body mass index was no different in women with or without AIP (Table 1). All women with AIP were

This article is protected by copyright. All rights reserved. 
parous and all but one woman (96\%) had given birth previously by cesarean section, compared to $33(33 \%)$ with normal placentation $(\mathrm{p}<0.001)$.

The maximum lower segment placental thickness was significantly greater in women with AIP as compared to those without ( $<<0.001$, Table 1, Figure 2). Figure 3 shows receiver operating characteristic (ROC) curve for the prediction of AIP by lower segment placental thickness, with an area under the curve of 0.826 (AUC 95\% CI; 0.749 to 0.904).

Details of the pregnancy outcome are shown in Table 2. Gestational age at delivery was significantly earlier in women with AIP. Although the median birthweight was significantly lower in women with AIP, it was due to earlier delivery since the birthweight centiles were no different (Table 2). As expected, the median blood loss and use of blood products were significantly higher in women with invasive placentation.

The gestational age at which the ultrasound examination was performed at which placental thickness measured was no different in the two groups. A significant correlation was found between gestational age at ultrasound and maximum placental thickness (spearman's rho = $0.188, p=0.031)$. Logistic regression analysis showed that only previous cesarean birth and placental thickness, but not gestational age at ultrasound, were independent predictors for AIP (Table 3). For each millimeter increase in placental thickness above the expected normal median, the odds for AIP increased 1.051 (95\% CI; 1.018 to 1.085). Prior cesarean birth considerably increased the odds for invasive placentation by 40 -fold (Table 3).

Excluded cases were significantly younger, and were less likely to have undergone a previous cesarean section. Maternal height, BMI, parity, mode of conception, smoking status and gestational age at the ultrasound scan were no different between the two groups (data not shown). There were no cases of AIP in cases with unsuitable images, and the gestational age at delivery was no different from that of the study group.

\section{DISCUSSION}

The results of the study show that, in women with a low-lying placenta/placenta previa, the maximum placental thickness is significantly higher in the presence of AIP compared to normal placentation. These findings support the hypothesis that scar implantation is a likely etiological factor for the development of AIP. The strength of the association seen suggests

This article is protected by copyright. All rights reserved. 
that there is significant predictive value for the prospective identification of AIP in these women.

Antenatal detection is particularly important in cases of clinically relevant AIP(14). Indeed, in the current study, average blood loss was 1700mls in women with AIP and 11/28 (40\%) needed transfusion of blood products despite the use of intra-arterial occlusive devices. The frequency of need for blood products in those with low anterior placenta or placenta previa where the placenta was not morbidly adherent was lower (20\%). Previous reports have shown that the accuracy of ultrasound for the prenatal detection of AIP is high, but not diagnostic(5, $6,10)$. This is likely because many of the ultrasound markers are subjective, relying on visual appearances rather than objective ultrasound measurement. The findings of this study, that a mean difference of $20 \mathrm{~mm}$ in placental thickness between AIP and normal placentation confers an odds ratio of 20 for AIP, suggests the potential for the use of this marker. Further, prospective, studies are needed to assess whether this could be a good first line screening tool for referral of women with low placenta for expert assessment. The combination of such an objective ultrasound measure, together with the history of previous cesarean birth, may well provide improved antenatal detection of AIP in the future.

Maximum placental thickness increases with gestational age, with a thickness in excess of $50 \mathrm{~mm}$ between 32 and 34 weeks' gestation being above the $90^{\text {th }}$ centile(15). It is interesting to note that 12 of the 28 (42\%) women with AIP showed an abnormally thick placenta at this stage, where the expected number with this thickness would have been three (10\%).

Why the prevalence of abnormally thick placenta is higher in women with AIP is uncertain, but this may be due to positioning or implantation of the placenta in the cesarean scar, thereby limiting migration of the placenta. This may result in a mushroom-like thickening of the placenta out of the scar defect rather than the usual pancake-like spread of the placenta over the uterine mucosa. It has been reported that lateral growth of the placenta occurs by trophoblast cell invasion of the decidual veins(16). The cesarean scar tissue is avascular and lacks decidua. This may explain why the placenta is thicker in the lower uterine segment in women with morbidly adherent placenta.

This article is protected by copyright. All rights reserved. 
In an earlier publication, excessively thick placenta was associated with a higher proportion of small for gestational age babies(15). The prevalence of small for gestational age fetuses in the current study was not unusually high, and no significant differences were seen between the birthweight centiles of cases with and without invasive placentation. This may be because the area of defective placentation is localised, and the rest of the placenta is able to function normally, compensating for the defective part of the morbidly adherent placenta.

The study is retrospective, and therefore placental thickness was not measured prospectively. This means that thickness was measured only on stored 2-D images, which may not have been representative of maximal placental thickness. However, the presence of other ultrasound signs suggestive of AIP is unlikely to have influenced measurement of placental thickness, as operators were not cognizant of the potential importance of placental thickness at the time. It is important to acknowledge that suitable images to assess placental thickness were not available in 33 women. Suitable images may not have been found if the placenta was not implanted in the anterior lower uterine segment. A vast majority of AIP are thought to be related to a defect in the cesarean section scar. This scar is expected to be on the anterior lower uterine segment. It is interesting that AIP was not seen in any of these 33 women from whom suitable images were not available. This sign may not work for AIP extending in the parametrium. Finally, the preliminary findings should be examined in prospective studies with specific reference to the sensitivity and specificity for AIP.

In conclusion, lower uterine segment placental thickness is increased in low-lying placentae of women with AIP compared to those with non-invasive placentation in this retrospective study, however, there is overlap in the two groups. This simple and pragmatic sign may be of clinical value in improving prenatal detection AIP in women with placental implantation in the lower uterine segment. Prospective studies are necessary to ascertain the screening performance of placental thickness for AIP.

This article is protected by copyright. All rights reserved. 


\section{REFERENCES}

1. Oyelese Y, Smulian JC. Placenta previa, placenta accreta, and vasa previa. Obstet Gynecol. 2006;107(4):927-41.

2. Silver RM. Abnormal Placentation: Placenta Previa, Vasa Previa, and Placenta Accreta. Obstet Gynecol. 2015;126(3):654-68.

3. Jauniaux E, Jurkovic D. Placenta accreta: pathogenesis of a 20th century iatrogenic uterine disease. Placenta. 2012;33(4):244-51.

4. Tikkanen M, Paavonen J, Loukovaara M, Stefanovic V. Antenatal diagnosis of placenta accreta leads to reduced blood loss. Acta Obstet Gynecol Scand. 2011;90(10):11406.

5. D'Antonio F, Iacovella C, Bhide A. Prenatal identification of invasive placentation using ultrasound: systematic review and meta-analysis. Ultrasound Obstet Gynecol. 2013;42(5):509-17.

6. Jauniaux E, Bhide A. Prenatal ultrasound diagnosis and outcome of placenta previa accreta after cesarean delivery: a systematic review and meta-analysis. Am J Obstet Gynecol. 2017;217(1):27-36.

7. Timor-Tritsch IE, Monteagudo A, Cali G, et al. Cesarean scar pregnancy and early placenta accreta share common histology. Ultrasound Obstet Gynecol. 2014;43(4):383-95.

8. Ben Nagi J, Ofili-Yebovi D, Marsh M, Jurkovic D. First-trimester cesarean scar pregnancy evolving into placenta previa/accreta at term. J Ultrasound Med. 2005;24(11):1569-73.

9. Cali G, Forlani F, Timor-Tritsch IE, Palacios-Jaraquemada J, Minneci G, D'Antonio F. Natural history of Cesarean scar pregnancy on prenatal ultrasound: the crossover sign. Ultrasound Obstet Gynecol. 2017;50(1):100-4.

10. Comstock CH, Love JJ, Jr., Bronsteen RA, et al. Sonographic detection of placenta accreta in the second and third trimesters of pregnancy. Am J Obstet Gynecol. 2004;190(4):1135-40.

11. Finberg HJ, Williams JW. Placenta accreta: prospective sonographic diagnosis in patients with placenta previa and prior cesarean section. J Ultrasound Med. 1992;11(7):33343.

12. Johnson T, Paterson-Brown S. Placenta praevia, placenta praevia accreta and vasa praevia: diagnosis and management. RCOG Green Top Guideline no 27: Royal College of Obstetricians and Gynecologists; 2011.

This article is protected by copyright. All rights reserved. 
13. Rozenberg P, Goffinet F, Phillippe HJ, Nisand I. Ultrasonographic measurement of lower uterine segment to assess risk of defects of scarred uterus. Lancet.

1996;347(8997):281-4.

14. Bhide A, Sebire N, Abuhamad A, Acharya G, Silver R. Morbidly adherent placenta: the need for standardization. Ultrasound Obstet Gynecol. 2017;49(5):559-63.

15. Elchalal U, Ezra Y, Levi Y, et al. Sonographically thick placenta: a marker for increased perinatal risk--a prospective cross-sectional study. Placenta. 2000;21(2-3):268-72.

16. Craven CM, Zhao L, Ward K. Lateral placental growth occurs by trophoblast cell invasion of decidual veins. Placenta. 2000;21(2-3):160-9.

This article is protected by copyright. All rights reserved. 


\section{FIGURE LEGENDS}

Figure 1: Measurement of maximum placental thickness in the lower segment in a typical case with abnormally invasive placenta. The placental thickness is significantly increased. Note also the presence of lacunae in the placenta.

Figure 2: Measurement of maximum placental thickness in the lower segment in a typical case with normal placentation. Upper border of the urinary bladder marks the limit of the lower uterine segment. Note the absence of other ultrasound signs of abnormally invasive placenta.

Figure 3. Maximum placental thickness in the lower segment in women with and without morbidly adherent placentation. Box represents the median, $1^{\text {st }}$ and $3^{\text {rd }}$ quartiles.

Figure 4. Receiver operating characteristic (ROC) curve of lower segment placental thickness and morbidly adherent placentation. The area under the curve $=0.826$ (95\% CI: 0.749 to 0.904$)$.

This article is protected by copyright. All rights reserved. 
Table 1 Baseline characteristics of the study population.

\begin{tabular}{|c|c|c|c|}
\hline Parameter & $\begin{array}{l}\text { Morbidly adherent } \\
\text { placentation } \\
\text { n }=28\end{array}$ & $\begin{array}{l}\text { Normal } \\
\text { placentation } \\
\mathrm{n}=\mathbf{1 0 3}\end{array}$ & Significance \\
\hline $\begin{array}{l}\text { Maternal age in years, Median } \\
\text { (IQR) }\end{array}$ & $36(32.5-39.8)$ & $34(32.0-38.0)$ & 0.507 \\
\hline $\begin{array}{l}\text { Maternal height in } \mathrm{cm} \text {, Mean } \\
\text { (SD) }\end{array}$ & $161.5(5.6)$ & $162.6(6.4)$ & 0.315 \\
\hline $\begin{array}{l}\text { Maternal weight in } \mathrm{Kg} \text {, Median } \\
\text { (IQR) }\end{array}$ & $68(61.8-80.2)$ & $67(60.3-75.0)$ & 0.431 \\
\hline Maternal BMI, Mean (SD) & $27.4(5.7)$ & $26.1(5.5)$ & 0.166 \\
\hline Nulliparity (n) & 0 & 14 & $0.03^{a}$ \\
\hline Smoker (n) & 3 & 6 & $0.07^{\mathrm{a}}$ \\
\hline IVF/ICI conception (n) & 0 & 6 & $\mathbf{0 . 0 3 7 ^ { \mathrm { a } }}$ \\
\hline Previous Cesarean delivery & 27 & 33 & $<0.001^{a}$ \\
\hline $\begin{array}{l}\text { Gestational age at ultrasound in } \\
\text { weeks, Median (IQR) }\end{array}$ & $34.5(31.0-36.1)$ & $\begin{array}{l}35.6(32.9- \\
36.6)\end{array}$ & 0.137 \\
\hline Mean booking $\mathrm{Hb}$ in $\mathrm{gm} / \mathrm{L}(\mathrm{SD})$ & $115(13)$ & $118(11)$ & 0.238 \\
\hline $\begin{array}{l}\text { Lower segment placental } \\
\text { thickness in mm, Median (Range) }\end{array}$ & $50.3(26.8-79.5)$ & $\begin{array}{l}30.9(10.9- \\
89.2)\end{array}$ & $<0.001$ \\
\hline
\end{tabular}

Values expressed as mean (SD) or median (IQR). Independent sample t test or Mann-Whitney U test used for comparison as appropriate. IQR, interquartile range; SD, standard deviation; BMI, body mass index; IVF, in vitro insemination: ICI, intracervical insemination.

${ }^{a}$ Chi squared test. Significant $\mathrm{p}$ values indicated in bold.

This article is protected by copyright. All rights reserved. 
Table 2. Pregnancy outcome.

\begin{tabular}{|c|c|c|c|}
\hline Parameter & $\begin{array}{l}\text { Morbidly adherent } \\
\text { placentation } \\
\mathrm{n}=\mathbf{2 8}\end{array}$ & $\begin{array}{l}\text { Normal } \\
\text { placentation } \\
\mathbf{n}=\mathbf{1 0 3}\end{array}$ & Significance \\
\hline $\begin{array}{l}\text { Gestation at birth in weeks, } \\
\text { Median (IQR) }\end{array}$ & $36.1(33.4-37.4)$ & $38.0(36.7-38.5)$ & 0.004 \\
\hline $\begin{array}{l}\text { Birthweight in g, Median } \\
\text { (IQR) }\end{array}$ & $\begin{array}{l}2715 \\
(2133-2995)\end{array}$ & $\begin{array}{l}3000 \\
(2640-3358)\end{array}$ & 0.007 \\
\hline Birthweight centile (SD) & $41.3(27.0)$ & $44.4(26.8)$ & 0.758 \\
\hline Male sex (n, \%) & $14(50.0 \%)$ & $65(63.1 \%)$ & 0.246 \\
\hline Hysterectomy (n) & 3 & 0 & $0.009^{a}$ \\
\hline $\begin{array}{l}\text { Operative blood loss in ml, } \\
\text { Median (IQR) }\end{array}$ & $\begin{array}{l}1700 \\
(1195-4500)\end{array}$ & $\begin{array}{l}800 \\
(600-1200)\end{array}$ & $<0.0005$ \\
\hline Blood transfusion $(\mathrm{n}, \%)$ & $11(39.3 \%)$ & $20(19.4 \%)$ & $0.001^{a}$ \\
\hline $\begin{array}{l}\text { Lowest post-op } \mathrm{Hb} \text { in } \mathrm{g} / \mathrm{L} \text {, } \\
\text { (SD) }\end{array}$ & $92(13)$ & $99(12)$ & 0.081 \\
\hline
\end{tabular}

Values expressed as mean (SD) or median (IQR). Independent sample $t$ test or Mann-Whitney U test used for comparison as appropriate. IQR, interquartile range; SD, standard deviation.

${ }^{\text {a }}$ Chi squared test. Significant $\mathrm{p}$ values indicated in bold.

Table 3. Results of the logistic regression analysis for the association with abnormally invasive placenta.

\begin{tabular}{lll}
\hline Variable & Adjusted odds ratio $(95 \%$ CI) & Significance \\
\hline Placental thickness $(\mathrm{mm})$ & $1.051(1.018-1.085)$ & $\mathbf{0 . 0 0 3}$ \\
Gestational age at ultrasound (weeks) & $0.955(0.823-1.107)$ & 0.538 \\
Previous Cesarean delivery & $40.6(5.1-320.8)$ & $<\mathbf{0 . 0 0 5}$
\end{tabular}

Significant $\mathrm{p}$ values indicated in bold.

This article is protected by copyright. All rights reserved. 

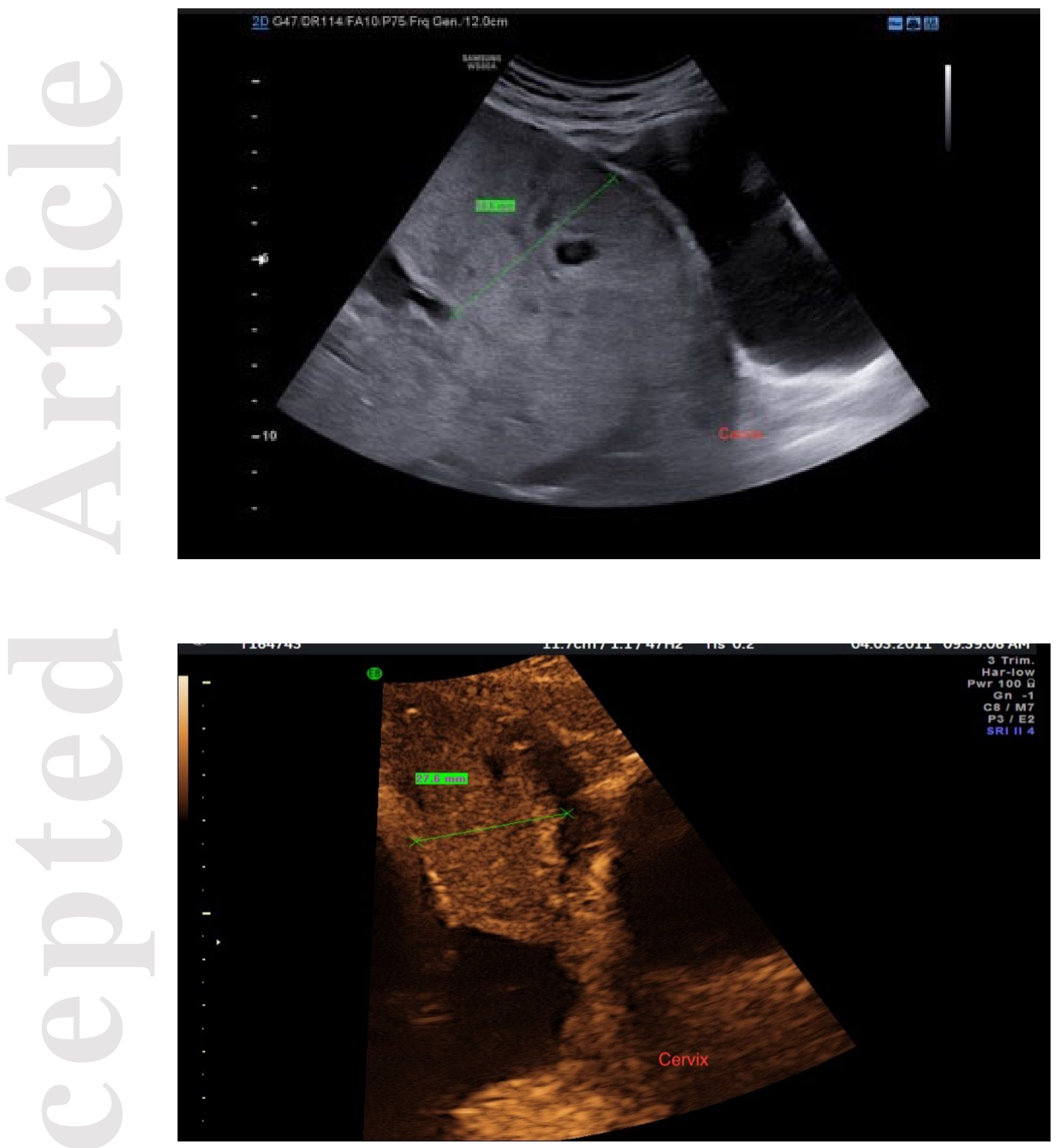

This article is protected by copyright. All rights reserved. 


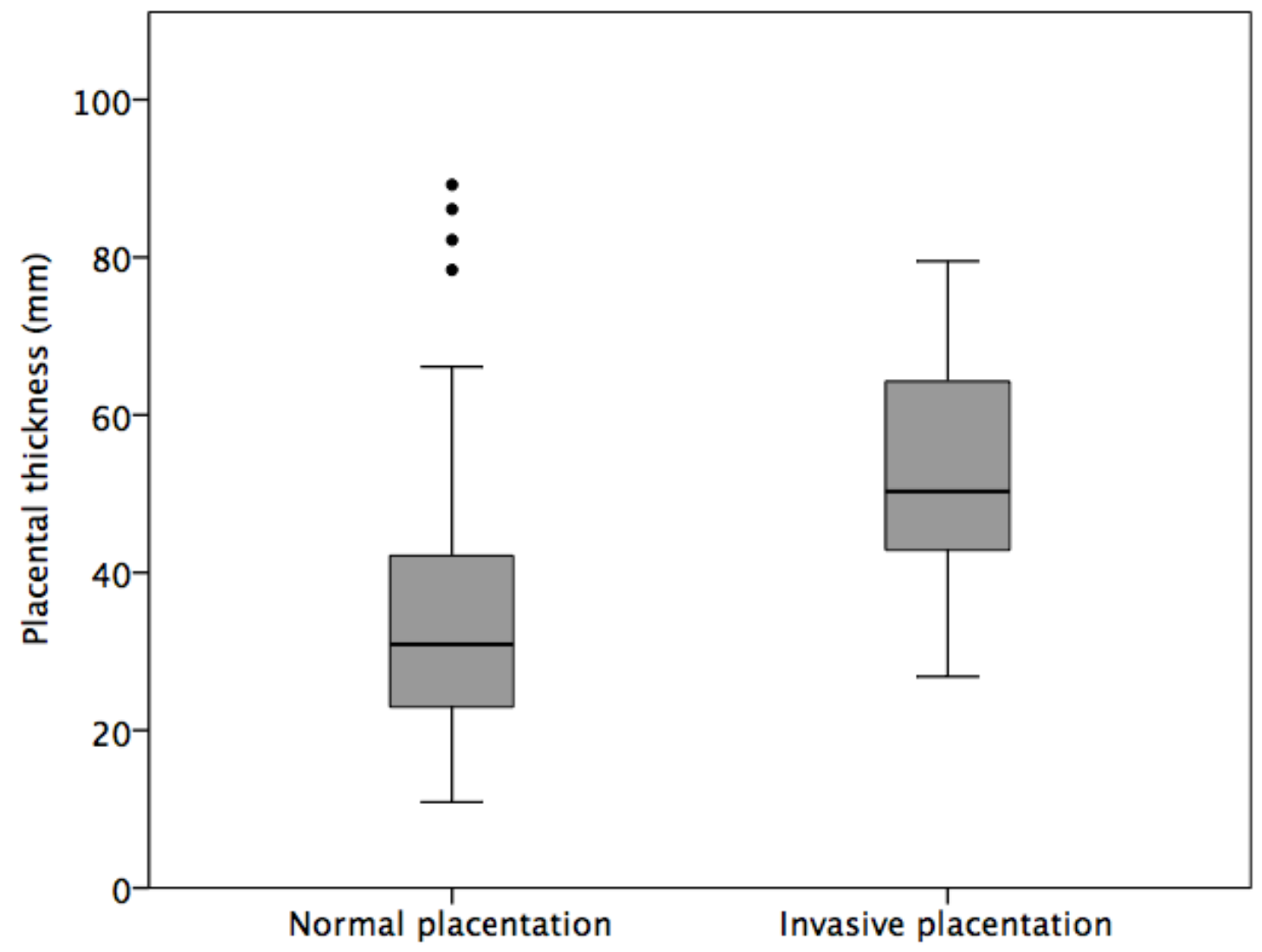

Final diagnosis 


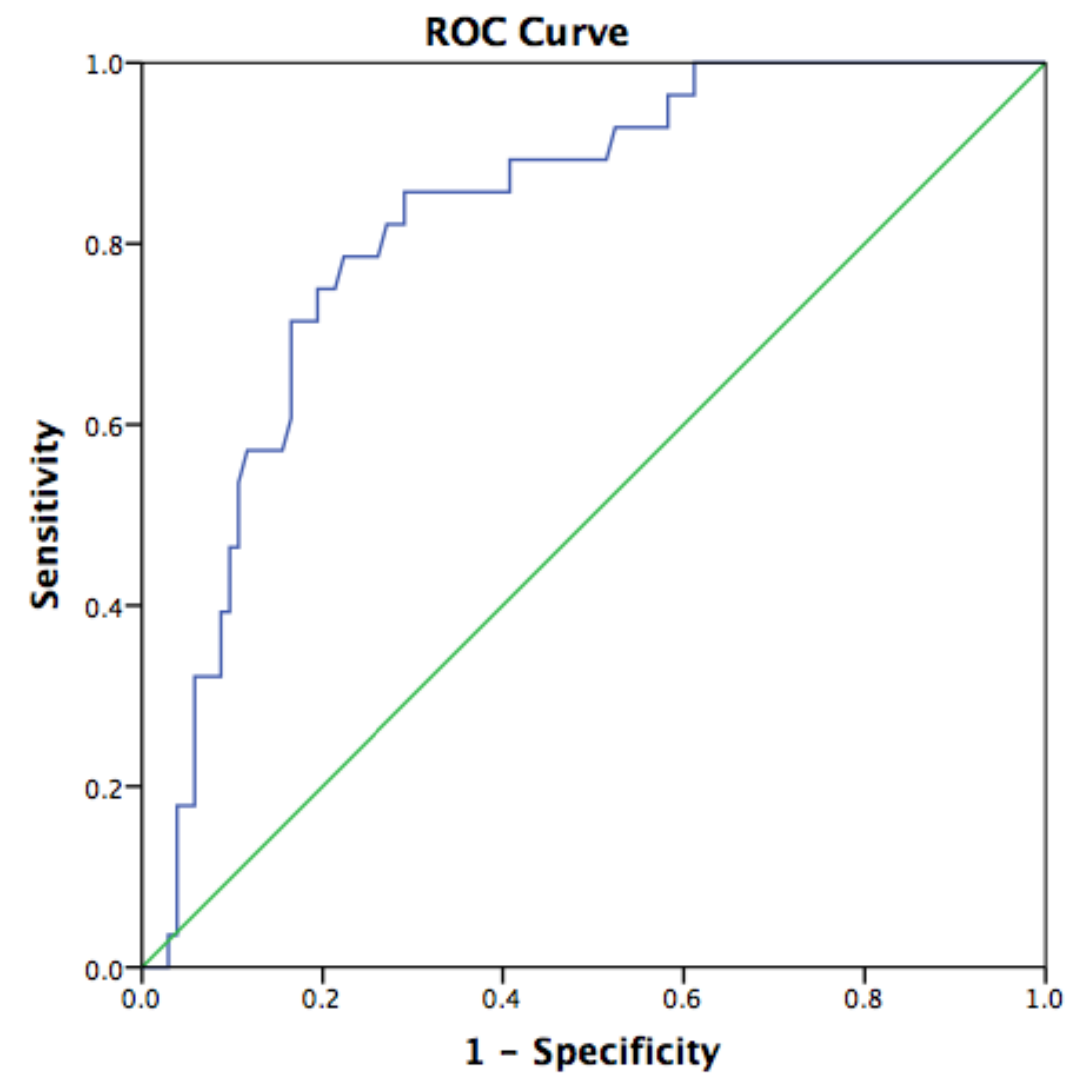

Diagonal segments are produced by ties. 